\title{
Atropine reduces dobutamine-induced side effects in ponies undergoing a pharmacological stress protocol
}

\author{
C. F. SANDERSEN ${ }^{\star}$, J. DETILLEUX $\dagger$, C. DELGUSTE, L. PIERARD ${ }^{\ddagger}$, G. vAN LOON§ and H. AMORY
}

Departments of Clinical Sciences, Large Animal Internal Medicine, ${ }^{\dagger}$ Animal Production, Quantitative Genetics, Faculty of Veterinary Medicine, and $¥$ Division of Cardiology, University Hospital Liège, University of Liège, Liege; and § Department of Internal Medicine and Clinical Biology of Large Animals, Ghent University, Merelbeke, Belgium.

Keywords: horse; cardiac arrhythmia; baroreceptor reflex; vagal tone; catecholamine; exercise intolerance

\section{Summary}

Reasons for performing study: High-dose dobutamine stress echocardiography has been shown to be cardiotoxic and arrhythmogenic in horses. However, the test may have benefit in practice as a pharmacological challenge of exercise without the treadmill being required.

Objectives: To investigate the effect of dobutamine on cardiac performance in ponies previously treated with atropine, in order to develop a pharmacological protocol that allows examination of the equine heart under stimulation.

Methods: In 13 healthy Shetland ponies, heart rate (HR), stroke index (SI) and cardiac index (CI) were calculated from pulsed-wave Doppler ultrasound measurements performed at rest and during incremental steps of dobutamine infusion. Group $1(\mathrm{n}=7)$ received dobutamine infusion at $2 \mu \mathrm{g} / \mathrm{kg} \mathrm{bwt} / \mathrm{min}$ for $5 \mathrm{mins}$ followed by incremental rates of $5 \mu \mathrm{g} / \mathrm{kg} \mathrm{bwt} / \mathrm{min}$ every $5 \mathrm{mins}$, from 5 to $40 \mu \mathrm{g} / \mathrm{kg}$ bwt $/ \mathrm{min}$. Group $2(\mathrm{n}=6)$ received dobutamine infusion in incremental rates of $1 \mu \mathrm{g} / \mathrm{kg} \mathrm{bwt} / \mathrm{min}$, every 5 mins, from $2 \mu \mathrm{g} / \mathrm{kg} \mathrm{bwt} / \mathrm{min}$ to $5 \mu \mathrm{g} / \mathrm{kg} \mathrm{bwt} / \mathrm{min}$, after premedication with 2 injections of $25 \mu \mathrm{g} / \mathrm{kg}$ bwt of atropine 5 mins apart.

Results: The increase in CI during the pharmacological challenge was higher in Group 2 and reached about 2.5 times the resting value. This increase in CI was mediated by a significant increase in HR in both groups, while SI significantly decreased in Group 1 and did not change significantly in Group 2. Ponies of Group 1, but not those of Group 2, showed excessive restlessness and cardiac arrhythmias during the pharmacological challenge and a high intragroup variability in cardiac response.

Conclusions: The results of this study suggest that a low dose of dobutamine in ponies previously given atropine could be a helpful pharmacological protocol to perform stress echocardiography in equids.

Potential relevance: Further studies should evaluate left ventricular wall motion in horses undergoing low-dose dobutamine protocol after pretreatment with atropine.

Introduction
Poor performance is a commonly reported problem among performance horses; after musculoskeletal and respiratory problems, cardiovascular problems are the third most common (Martin et al. 2000). However, some of these problems are subclinical or not present at rest and might be undiagnosed if the horse is not examined under exercising conditions (Reef 2001). Although the use of a treadmill allows examination of the heart under exercising conditions, it is expensive, not always available, requires skilled personal and does not allow echocardiography to be performed during exercise. Pharmacological stress testing would avoid most of the problems related to treadmill exercise. Furthermore, it would allow performance of echocardiography during cardiac stimulation and not only after cessation of the exercise, which might be helpful in the detection of exercisedinduced pathologies (Frye et al. 2003).

Dobutamine stress echocardiography has been studied in horses and, although chronotropic and inotropic changes induced by a high dose were similar to those induced by exercise it was not recommended because of its potential arrhythmogenic and cardiomyotoxic effect (Frye et al. 2003).

In human pharmacological stress tests, dobutamine is combined with atropine in patients who do not respond with a sufficient increase in heart rate (HR) (Mc Neill et al. 1992) or in those developing paradoxic sinus deceleration in response to dobutamine (Brofferio et al. 2002). The use of atropine reduced pharmacological test time and dobutamine doses required for sufficient cardiac stimulation (Lessick et al. 2000).

The purpose of this study was to compare the effects of highdose dobutamine with a combined atropine/low-dose dobutamine protocol on stroke volume and cardiac output, as indicators of global cardiac function, in order to evaluate the latter as a potential protocol for equine stress echocardiography.

Materials and methods

Animals

Thirteen male Shetland ponies age 6 months -9 years (mean \pm s.d. $3.2 \pm 2.6$ years) and weighing $80-182 \mathrm{~kg}$ (mean \pm s.d. $112.2 \pm 41$ $\mathrm{kg}$ ) were studied. The ponies were divided randomly into 2 groups. Group 1 consisted of 7 ponies weighing 96-113 kg (mean \pm s.d. $114.8 \pm 11.6 \mathrm{~kg}$ ) and Group 2 of 6 ponies weighing $80-182$

*Author to whom correspondence should be addressed.

[Paper received for publication 00.00.00; Accepted 00.00.00] 
TABLE 1: Heart rate, cardiac index, stroke index, maximal velocity of aortic flow and velocity time integral in ponies receiving high-dose dobutamine infusion

\begin{tabular}{lcccccccc}
\hline & \multicolumn{7}{c}{ Dose of dobutamine $(\mu \mathrm{g} / \mathrm{kg}$ bwt/min) } \\
\cline { 2 - 9 } & 0 & 2 & 5 & 10 & 15 & 20 & 25 & 30 \\
\hline No. ponies & 7 & 7 & 7 & 7 & 7 & 7 & 6 & 6 \\
HR (beats/min) & $51.2 \pm 10.8$ & $46.7 \pm 10.4$ & $46.5 \pm 10.2$ & $48.9 \pm 10.1$ & $67.0 \pm 10.1^{\S}$ & $86.4 \pm 10.2^{\S *}$ & $121.9 \pm 10.7^{\S *}$ & $129.6 \pm 11.1^{*}$ \\
Cl (ml/kg bwt/min) & $118.0 \pm 21.2$ & $95.0 \pm 20.3$ & $117.0 \pm 20.0$ & $121.1 \pm 19.6$ & $124.6 \pm 20.0$ & $147.6 \pm 20.1$ & $193.3 \pm 21.3^{*}$ & $204.9 \pm 22.2^{*}$ \\
SI (ml/kg bwt) & $2.58 \pm 0.32$ & $2.38 \pm 0.32$ & $2.91 \pm 0.31$ & $2.83 \pm 0.31$ & $2.25 \pm 0.31^{\S}$ & $2.23 \pm 0.31$ & $1.86 \pm 0.32^{*}$ & $1.79 \pm 0.33^{*}$ \\
$V_{\max }(\mathrm{m} / \mathrm{sec})$ & $0.840 \pm 0.057$ & $0.880 \pm 0.055$ & $1.040 \pm 0.054^{\star}$ & $1.020 \pm 0.053^{*}$ & $1.053 \pm 0.053^{*}$ & $1.080 \pm 0.053^{*}$ & $1.060 \pm 0.056^{*}$ & $1.060 \pm 0.058^{*}$ \\
VTI (cm) & $24.10 \pm 1.82$ & $22.60 \pm 1.75$ & $25.50 \pm 1.72^{\S}$ & $24.80 \pm 1.70$ & $19.90 \pm 1.70^{\S}$ & $19.30 \pm 1.72^{*}$ & $16.60 \pm 1.80^{*}$ & $17.20 \pm 1.88^{*}$ \\
\hline
\end{tabular}

$\mathrm{HR}=$ heart rate; $\mathrm{Cl}=$ cardiac index; $\mathrm{SI}=$ stroke index; $\mathrm{V}_{\max }=$ maximal velocity of aortic flow; VTI = velocity time integral. Values expressed in least square means \pm s.e. *Significantly different from baseline values; §significantly different from preceding dose $(P<0.05)$.

$\mathrm{kg}$ (mean \pm s.d. $112.2 \pm 40 \mathrm{~kg}$ ). The ponies were considered to be healthy based on clinical and routine Doppler echocardiographic examination. One hour before the protocol, a 16 gauge catheter (Intraflon2) ${ }^{1}$ was inserted into the left jugular vein under local anaesthesia and aseptic conditions. Ponies were monitored for appetite, HR and intestinal sounds for $8 \mathrm{~h}$ after the protocol. The protocol was approved by the ethical committee of the University of Liège.

\section{Echocardiographic measurements}

Doppler echocardiographic examinations were performed with a Vingmed CFM $725^{2}$ machine equipped with a $2.5 \mathrm{MHz}$ phased array sector transducer and recorded on S-VHS tape. Simultaneously, an apex-base ECG was recorded. Heart rate was calculated from 10 consecutive QRS intervals. Aortic diameter was measured once before onset of pharmacological stimulation during systole from the right parasternal long axis left ventricular outflow tract view using the leading edge to leading edge method at the aortic valvular annulus. The mean of at least 3 measurements was used to calculate the cross-sectional area, assuming a circular and constant orifice. The aortic flow velocities were recorded in pulsed-wave Doppler mode from a left parasternal left outflow tract view. The ultrasound beam was aligned as parallel to blood flow as possible to record maximal velocities the with the sample volume of $6 \mathrm{~mm}$ placed at the aortic annular level. Aortic flow velocities were measured from the recordings, by tracing the modal velocity envelope of the pulsed wave Doppler signal planimetrically using the software of the ultrasound device.

The mean of at least 3 good quality velocity time integrals (VTI) was used. Stroke index (SI) was calculated as follows:

$$
\mathrm{SI}=(\text { aortic diameter } / 2)^{2} * \pi * \mathrm{VTI} / \mathrm{kg} \text { bwt }
$$

Cardiac index (CI) was calculated as the product of SI and HR.

Study design

The ponies of Group 1 underwent the following protocol: after baseline aortic diameter and aortic flow recordings, dobutamine (Dobutrex) ${ }^{3}$ was injected by means of an infusion pump (Model $960)^{4}$ at a rate of $2 \mu \mathrm{g} / \mathrm{kg} \mathrm{bwt} / \mathrm{min}$ for $5 \mathrm{mins}$, then the infusion rate was increased to $5 \mu \mathrm{g} / \mathrm{kg} \mathrm{bwt} / \mathrm{min}$ for $5 \mathrm{mins}$ and further increased every $5 \mathrm{mins}$ in incremental steps of $5 \mu \mathrm{g} / \mathrm{kg} \mathrm{bwt} / \mathrm{min}$ until a maximal dose of $40 \mu \mathrm{g} / \mathrm{kg}$ bwt $/ \mathrm{min}$ was reached.

The ponies of Group 2 underwent the following protocol: after baseline aortic diameter and flow were recorded, atropine (crystalline powder in $1 \%$ aqueous solution) was injected i.v. at a dose of $25 \mu \mathrm{g} / \mathrm{kg}$ bwt. Three mins after the injection, aortic flow was recorded. Five mins after the first injection, a second dose of $25 \mu \mathrm{g} / \mathrm{kg}$ bwt atropine was given. Five mins after the second injection, dobutamine was infused at a rate of $2 \mu \mathrm{g} / \mathrm{kg} \mathrm{bwt} / \mathrm{min}$ and then increased every 5 mins in incremental steps of $1 \mu \mathrm{g} / \mathrm{kg}$ bwt $/ \mathrm{min}$ until an infusion rate of $5 \mu \mathrm{g} / \mathrm{kg}$ bwt $/ \mathrm{min}$ was reached.

In both groups, dobutamine infusion was stopped after a maximal HR of 170 beats/min was reached. Furthermore, infusion was stopped immediately when ventricular tachycardia became apparent or the pony showed adverse reactions. At each incremental step, aortic flow was recorded between the 3rd and 5 th min after the onset of each infusion step in order to reach a steady state cardiac response to dobutamine.

\section{Statistical analysis}

Each variable was analysed separately with a 2-group repeated measures model with an auto-regressive variance-covariance matrix for the repeated measures (Proc mixed, SAS/STAT software $)^{5}$. Least-squares means were computed for each group and each dose within group.

\section{Results}

\section{Dosage administration}

Group 1: All ponies showed varying degrees of restlessness, including pawing, stamping, stepping back and forth, head shaking and tail twitching at dobutamine doses above $10 \mu \mathrm{g} / \mathrm{kg} \mathrm{bwt} / \mathrm{min}$. Moreover, in one pony coughing was observed at a dose of $15 \mu \mathrm{g} / \mathrm{kg} \mathrm{bwt} / \mathrm{min}$, in another trembling was observed at a dose of $20 \mu \mathrm{g} / \mathrm{kg} \mathrm{bwt} / \mathrm{min}$ and tachypnoea was observed at a dose of 30 $\mu \mathrm{g} / \mathrm{kg} \mathrm{bwt} / \mathrm{min}$ in a third pony. The infusion was discontinued after the dose of $20 \mu \mathrm{g} / \mathrm{kg}$ bwt $/ \mathrm{min}$ in one pony and $30 \mu \mathrm{g} / \mathrm{kg} \mathrm{bwt} / \mathrm{min}$ in 3 other ponies because HR exceeded 170 beats/min. In another pony, the infusion had to be stopped at a dose of $35 \mu \mathrm{g} / \mathrm{kg}$ bwt $/ \mathrm{min}$ because of excessive restlessness. The only 2 ponies that were submitted to the rate of $40 \mu \mathrm{g} / \mathrm{kg}$ bwt $/ \mathrm{min}$ did not show expected tachycardia at this maximal level of pharmacological challenge. One pony developed 2nd degree AV-block at doses of 5 and 10 $\mu \mathrm{g} / \mathrm{kg} \mathrm{bwt} / \mathrm{min}$. All ponies developed transient sinus arrhythmia during the pharmacological stimulation, one pony at the dose of 10 $\mu \mathrm{g} / \mathrm{kg} \mathrm{bwt} / \mathrm{min}$, which turned to regular sinus rhythm at the dose of $20 \mu \mathrm{g} / \mathrm{kg} \mathrm{bwt} / \mathrm{min}$, one at the dose of $15 \mu \mathrm{g} / \mathrm{kg} \mathrm{bwt} / \mathrm{min}$ and 3 at a dose of $20 \mu \mathrm{g} / \mathrm{kg} \mathrm{bwt} / \mathrm{min}$. All showed regular sinus rhythm at the 
TABLE 2: Heart rate, cardiac index, stroke index, maximal velocity of aortic flow and velocity time integral in pretreated ponies receiving low-dose dobutamine infusion

\begin{tabular}{|c|c|c|c|c|c|c|c|}
\hline & \multirow[b]{2}{*}{0} & \multicolumn{2}{|c|}{ Atropine $(\mu \mathrm{g} / \mathrm{kg} \mathrm{bwt})$} & \multicolumn{4}{|c|}{ Dobutamine $(\mu \mathrm{g} / \mathrm{kg}$ bwt/min) } \\
\hline & & 25 & 25 (after 5 mins) & 2 & 3 & 4 & 5 \\
\hline No. ponies & 6 & 6 & 6 & 6 & 6 & 6 & 5 \\
\hline HR (beats/min) & $52.7 \pm 11.7$ & $82.0 \pm 11.3^{*}$ & $82.4 \pm 11.1^{*}$ & $119.1 \pm 11.0^{\S *}$ & $135.0 \pm 11.1^{\S *}$ & $154.3 \pm 11.4^{\S^{*}}$ & $167.8 \pm 12.2^{\star \ddagger}$ \\
\hline $\mathrm{Cl}$ (ml/kg bwt/min) & $127.9 \pm 22.9$ & $176.5 \pm 22.0^{*}$ & $197.2 \pm 21.7^{*}$ & $255.1 \pm 21.6 ో+\dagger$ & $272.2 \pm 21.7 \S * \dagger$ & $272.3 \pm 22.1^{\star}+$ & $295.4 \pm 24.5^{\star} \dagger$ \\
\hline $\mathrm{SI}(\mathrm{ml} / \mathrm{kg} \mathrm{bwt})$ & $2.19 \pm 0.35$ & $2.11 \pm 0.34$ & $2.39 \pm 0.34$ & $2.21 \pm 0.34$ & $2.06 \pm 0.34$ & $1.85 \pm 0.35$ & $1.80 \pm 0.36$ \\
\hline $\mathrm{V}_{\max }(\mathrm{m} / \mathrm{sec})$ & $0.81 \pm 0.061$ & $0.86 \pm 0.059$ & $0.87 \pm 0.058$ & $0.90 \pm 0.058$ & $1.00 \pm 0.058 \S$ & $0.99 \pm 0.060^{*}$ & $1.00 \pm 0.064^{*}$ \\
\hline VTI $(\mathrm{cm})$ & $21.02 \pm 1.98$ & $17.31 \pm 1.90^{\S *}$ & $22.26 \pm 1.86^{*}$ & $19.77 \pm 1.86$ & $18.17 \pm 1.87$ & $16.43 \pm 1.91$ & $15.67 \pm 2.07^{\star}$ \\
\hline
\end{tabular}

$\mathrm{HR}=$ heart rate $\mathrm{CI}=$ cardiac index; $\mathrm{SI}=$ stroke index; $\mathrm{V}_{\max }=$ maximal velocity of aortic flow; $\mathrm{VTI}=$ velocity time integral. Values expressed in least square means \pm s.e. *Significantly different from baseline values; §significantly different from preceding dose; ${ }^{\dagger}$ significantly higher than $\mathrm{Group} 1$ at doses of $2-25 \mu \mathrm{g} / \mathrm{kg}$ bwt/min; ${ }^{\ddagger}$ significantly higher than Group 1 at $30 \mu \mathrm{g} / \mathrm{kg} \mathrm{bwt} / \mathrm{min}(\mathrm{P}<0.05)$.

dose of $25 \mu \mathrm{g} / \mathrm{kg}$ bwt $/ \mathrm{min}$ and 2 ponies at the dose of $35 \mu \mathrm{g} / \mathrm{kg}$ bwt/min. One pony showed isolated premature ventricular complexes and one multiple premature ventricular complexes at an infusion rate of $20 \mu \mathrm{g} / \mathrm{kg} \mathrm{bwt} / \mathrm{min}$. All cardiac arrhythmias disappeared within 30 secs after the infusion had been stopped.

Group 2: Only a transient slight restlessness was observed in 3 ponies during dobutamine challenge. None of the 6 ponies showed arrhythmia during the test. All ponies received the final dose of $5 \mu \mathrm{g} / \mathrm{kg}$ bwt $/ \mathrm{min}$, although echocardiographic measurements were impossible in one pony at this dose, due to aliasing.

None of the ponies showed obvious signs of colic, in 2 ponies appetite was diminished for approximately $1 \mathrm{~h}$ after the end of the procedures and HR returned to baseline values in all ponies within 3-4 $\mathrm{h}$ after the end of the procedures.

\section{Cardiac parameters}

Mean HR, SI, CI, aortic VTI and aortic maximal velocity $\left(\mathrm{V}_{\max }\right)$ obtained in Groups 1 and 2 at baseline and at each step of the pharmacological challenge are listed in Tables 1 and 2, respectively.

Cardiac index: In Group 1, only 3 ponies underwent the dose of 35 $\mu \mathrm{g} / \mathrm{kg} \mathrm{bwt} / \mathrm{min}$ and two $40 \mu \mathrm{g} / \mathrm{kg}$ bwt/min, which made statistical comparison of these steps difficult. In Group 1, mean CI remained statistically unchanged from baseline values until an infusion rate of $20 \mu \mathrm{g} / \mathrm{kg}$ bwt $/ \mathrm{min}$. Mean CI at infusion rates from 25 to $30 \mu \mathrm{g} / \mathrm{kg}$ bwt/min were significantly $(\mathrm{P}<0.05)$ higher than basal values. In Group 2, mean CI was significantly higher at all steps of pharmacological stimulation than controls. There was no significant difference in mean CI between the first and the second dose of atropine. Mean CI was significantly higher at each incremental step of the dobutamine infusion than at the previous one. Mean CI values at dobutamine infusion rates of 2 to $5 \mu \mathrm{g} / \mathrm{kg}$ bwt $/ \mathrm{min}$ were significantly higher than those obtained in Group 1 at dobutamine infusion rates of 2 to $25 \mu \mathrm{g} / \mathrm{kg}$ bwt $/ \mathrm{min}$.

Heart rate: In Group 1, mean HR decreased compared with resting values, although not significantly, at dobutamine infusion rates of 2 to $10 \mu \mathrm{g} / \mathrm{kg} \mathrm{bwt} / \mathrm{min}$. From rates of $15 \mu \mathrm{g} / \mathrm{kg}$ bwt $/ \mathrm{min}$, mean HR increased significantly at each incremental step until a mean \pm s.e. $\mathrm{HR}$ of $130 \pm 11$ beats/min that was reached at a dobutamine infusion rate of $30 \mu \mathrm{g} / \mathrm{kg}$ bwt/min. In Group 2, mean HR was higher at each step of cardiac stimulation than at rest. Mean HR was not significantly different between the first and the second dose of atropine, but mean HR increased significantly at each step of dobutamine challenge. The highest mean \pm s.e. HR of $168 \pm 13$ beats $/ \mathrm{min}$ was reached at an infusion rate of $5 \mu \mathrm{g} / \mathrm{kg} \mathrm{bwt} / \mathrm{min}$. Mean HR obtained in Group 2 was significantly higher at a dobutamine infusion rate of $5 \mu \mathrm{g} / \mathrm{kg}$ bwt $/ \mathrm{min}$ than in Group 1 at a rate of $30 \mu \mathrm{g} / \mathrm{kg}$ bwt $/ \mathrm{min}$.

Stroke index: In Group 1, mean SI obtained at doses from 2 to 10 $\mu \mathrm{g} / \mathrm{kg}$ bwt $/ \mathrm{min}$ were not significantly $(\mathrm{P}=)$ different from resting values. Mean SI at infusion rates of $15-40 \mu \mathrm{g} / \mathrm{kg}$ bwt $/ \mathrm{min}$ were significantly $(\mathrm{P}=)$ lower than at the rate of $5 \mu \mathrm{g} / \mathrm{kg} \mathrm{bwt} / \mathrm{min}$. In Group 2, changes in mean SI were not significantly different from resting values during the pharmacological challenge, even though a downward trend was observable. There was no significant difference in mean SI response between the 2 groups.

Maximal velocity of aortic flow: In Group 1 , mean $\mathrm{V}_{\max }$ was significantly higher at all steps of dobutamine infusion than controls. In Group 2, mean $\mathrm{V}_{\max }$ was significantly higher during all incremental steps of dobutamine infusion than baseline values and after the 2 injections of atropine. Mean $\mathrm{V}_{\max }$ obtained in Group 1 at each step of dobutamine infusion was significantly higher than values obtained in Group 2 after the 2 injections of atropine.

\section{Discussion}

In man, dobutamine is known to be a potent $\beta_{1}$ agonist and to have a positive inotropic and chronotropic effect, a rapid onset of action and a short half-life (Tuttle and Mills 1975). Given the dosedependent manner and knowing that the equine myocardium is predominantly covered by $\beta_{1}$ receptors, a similar response could be expected in horses (Horn et al. 2002). However, in this study, mean HR did not change until a dose rate of $15 \mu \mathrm{g} / \mathrm{kg}$ bwt $/ \mathrm{min}$ of dobutamine was reached. Furthermore, 2 ponies in Group 1 failed to increase $\mathrm{HR}$, and therefore $\mathrm{CI}$, to an expected level in response to dobutamine. The cause of this diminished chronotropic effect is unclear, but a parasympathetically mediated high-pressure baroreceptor reflex has been suggested to be the cause in dogs (Liang and Hood 1979). In the present study, systolic arterial pressure was not measured. However, the results of a study by Hinchcliff et al. (1991) support a role of the baroreceptor reflex in the inotropic and chronotropic effect of dobutamine in horses. In the latter study, dobutamine at a dose of $0.5 \mu \mathrm{g} / \mathrm{kg} \mathrm{bwt} / \mathrm{min}$ increased systolic, diastolic and mean systemic arterial pressures in both pretreated and nonpretreated horses, but increased HR only in horses pretreated with atropine. Apparently, the chronotropic effect of dobutamine was opposed by a reflex increase in parasympathethic tone in nonpretreated horses. In pretreated horses, atropine blocked the reflex bradycardic effect induced by systemic 
hypertension and, therefore permitted expression of the positive chronotropic activity of dobutamine (Hinchcliff et al. 1991).

In our study, HR and CI increased significantly while SI slightly decreased in response to atropine. Stroke volume (SV) is determined by the interaction of 4 factors; myocardial contractility, preload, afterload and HR (Smith and Kampine 1984). Atropine administration in horses increases the HR approximately 2-fold, decreases the SV to half of basal values (Hinchcliff et al. 1991) and is associated with sharp reductions in right ventricular end-diastolic volume and pressure, suggesting a decrease in right ventricular preload, and an increase in mean arterial pressure, suggesting an increase in left ventricular afterload (Hinchcliff et al. 1991). These changes, without an increase in myocardial contractility, could explain the atropineinduced decrease in SI. The effects of changes in HR on SI are complex since HR influences afterload, preload and myocardial contractility. An increase in HR decreases preload and increases afterload and myocardial contractility (Berne and Levy 1988). Since atropine does not affect venous tone (Alexander 1963), it seems that atropine-induced increased HR and the reduced preload are the result of a reduction in diastolic filling time and an unchanged venous return. In man, dobutamine, like muscular exercise, is known to decrease vascular resistance. However, unlike exercise, during dobutamine infusion venous return is not increased (Pierard et al. 1989) and left ventricular volume decreases (Olsen et al. 1994). The decreases in venous return and systemic vascular resistance, as well as the shortened time for ventricular filling at high HR, may contribute to the decreases in ventricular volumes and SV observed with high doses of dobutamine (Pellikka et al. 1995).

Dobutamine-induced atrioventricular blocks are observed only rarely in man (Secknus and Marwick 1997) and it is unclear whether they are due to a vagal reflex or induced by myocardial ischaemia (Hung et al. 1999). In our study, the occurrence of atrioventricular blocks seems to be due to a vagal reflex, since second degree atrioventricular block was observed only in nonpretreated ponies, not in ponies pretreated with atropine.

Complex ventricular arrhythmias during dobutamine stress echocardiography are rare in man and occur more frequently in patients with a previous myocardial infarction, suggesting that the occurrence of dobutamine-induced ventricular dysrhythmia may be related to left ventricular dysfunction (De Sutter et al. 2003).

In conscious healthy horses, dobutamine-induced ventricular arrhythmias appear to be a more common problem than in man. The reason for this has not yet been elucidated, but two factors might contribute to the occurrence of ventricular ectopy in horses receiving dobutamine; the presence of vagally-mediated rhythms that remove overdrive suppression of an enhanced ventricular escape rhythm, and the inherent ability of dobutamine to induce such arrhythmias (Frye et al. 2003). The arrhythmogenic properties of dobutamine might be attributed to $\beta_{1}$ receptor stimulation, reduction in plasma potassium concentration (Goldenberg et al. 1989), enhanced automaticity and alterations in ventricular refractoriness and repolarisation (Stump et al. 2000). In the present study, no ventricular arrhythmias were observed during dobutamine infusion in pretreated ponies, which might support the hypothesis of an influence of vagal tone. However, the infusion rate used in the pretreated ponies was much lower than in the nonpretreated ones, precluding comparison of the arrhythmogenic effects of dobutamine in the 2 groups. Nevertheless, the target HR of 170 beats/min was obtained in the pretreated group without any arrhythmia. Moreover, the intragroup variability in cardiac response to the pharmacological challenges was clearly wider in the group submitted to the highdose dobutamine regimen.

Doppler echocardiography is not a precise method for the measurement of cardiac output, but several studies have demonstrated a reasonable correlation between this method and the thermodilution method (Stadler et al. 1994; Blissitt et al. 1997). To limit errors in cardiac outflow measurements, the angle between the ultrasound beam and the actual flow should be below $20^{\circ}$. Wider angles lead to underestimation, while the use of correcting built-in software of ultrasound devices leads to overestimation of flow (Reef et al. 1989). The difference between the 2 techniques increases with cardiac output (Blissitt et al. 1997). Movement of the aortic root toward the ultrasound transducer during systole leads to underestimation of the flow velocity (Erikson and Walloe 1990). Furthermore, during the dobutamine infusion in the present study an increased dispersion of the signal was observed, which made it more difficult to identify modal envelopes accurately. This observation is consistent with findings of Blissitt et al. (1997). Although Doppler echocardiography is related to certain inaccuracies, it has the major advantage of noninvasiveness. In our study, angles varied between $34-47^{\circ}$, but the errors in Doppler-derived cardiac output estimate have been neglected, since the aim of the study was to compare 2 different pharmacological protocols on global cardiac performance. The same method was used during the 2 protocols, which implies that error due to the measurement technique would be similar.

Although the accumulated dose of $50 \mu \mathrm{g}$ atropine is slightly higher than the dose commonly used in horses, no adverse reaction was observed. These observations are consistent with earlier studies in which 5 ponies were given $44 \mu \mathrm{g} / \mathrm{kg}$ bwt atropine i.v. and only a transient loss of appetite was observed in all of the ponies, with one pony experiencing colic signs which disappeared spontaneously (Ducharme and Fubini 1983).

In conclusion, at least some of the side effects observed in horses submitted to high-dose dobutamine challenge are probably due to activation of a vagal reflex. Atropine premedication inhibits this vagal reflex and 1) allows reduction of the dobutamine dose by almost 10 times while inducing a similar a cardiac stimulation, 2) drastically reduces side effects related to higher doses of dobutamine and 3) reduces individual variation in the response of cardiac function to dobutamine challenge. The administration of low-dose dobutamine in ponies pretreated with atropine seems to be safe and efficient. This pharmacological protocol should be studied further to investigate its effects on left ventricular function in healthy horses and in horses with suspected exercise-induced myocardial dysfunction.

\section{Acknowledgements}

This study was supported by Skill Animal Health, France, The 'Fondation Prince Laurent' and the 'Fond Spéciaux de la Recherche'.

\section{Manufacturers' addresses}

${ }^{1}$ Vygon, Ecouen, France.

${ }^{2}$ Skill Animal Health Systems, Strasbourg, France.

${ }^{3}$ Lilly, Brussels, Belgium.

${ }^{4}$ Imed, San Diego, California, USA.

${ }^{5}$ SAS Institute Inc., Cary, North Carolina, USA. 


\section{References}

Alexander, R.S. (1963) The peripheral venous system. In: Handbook of Physiology Section Circulation, Vol. II, Eds: W.F. Hamilton and P. Dow, American Physiology Society, Washington. pp 1075-1098.

Berne, R.M. and Levy, M.N. (Eds) (1988) Control of cardiac output: coupling of heart and blood vessels. In: Physiology, Mosby Co., St. Louis. pp 525-539.

Blissitt, K.J., Young, L.E., Jones, R.S., Darke, P.G.G. and Utting, J. (1997) Measurement of cardiac output in standing horses by Doppler echocardiography and thermodilution. Equine vet. J. 29, 18-25.

Brofferio, A., Alaeddini,. J, Oommen, R., Di Bitetto, T., Shalomoff, Y., Ilercil, A. and Shirani, J. (2002) Effect of early administration on paradoxic sinus deceleration during dobutamine stress echocardiography. Am. J. Cardiol. 89, 645-647.

De Sutter, J., Poldermans, D., Vourvouri, E., Van Donburg, R., Elhendy, A., Bax, J., Sozzi, F., Jordaens, L., De Buyzere, M. and Roelandt, J. (2003) Long-term prognostic significance of complex ventricular arrhythmias induced during dobutamine stress echocardiography. Am. J. Cardiol. 91, 242-244.

Ducharme, N.G. and Fubini, S.L. (1983) Gastrointestinal complications associated with the use of atropine in horses. J. Am. vet. med. Ass. 182, 229-231.

Erikson, M. and Walloe, L. (1990) Improved method for cardiac output determination in man using ultrasound Doppler technique. Med. Biol. Eng. Comp. 28, 555-560.

Frye, M.A., Bright, J.M., Dargatz, D.A., Fettmann, M.J., Frisbie, D.D., Baker, D.C. and Traub-Dargatz, J.L. (2003) A comparison of dobutamine infusion to exercise as a cardiac stress test in healthy horses. J. vet. intern. Med. 17, 58-64.

Goldenberg, I.F., Olivari, M.T., Levine, T.B. and Cohn, J.N. (1989) Effect of dobutamine on plasma potassium in congestive heart failure secondary to idiopathic or ischemic cardiomyopathy. Am. J. Cardiol. 63, 843-846.

Hinchcliff, K.W., McKeever., K.H. and Muir, W.W. III (1991) Hemodynamic effects of atropine, dobutamine, nitroprussid, phenylephrine, and propanolol in conscious horses. J. vet. intern. Med. 5, 80-86.

Horn, J., Bailey, S., Berhane, Y., Marr, C.M. and Elliott, J. (2002) Density and binding characteristics of beta-adrenoceptors in the normal and failing equine myocardium. Equine vet. J. 34, 411-416.

Hung, K.C., Lin, F.C., Chern, M.S., Chang, H.J., Hsieh, I.C. and Wu, D. (1999) Mechanisms and clinical significance of transient atrioventricular block during dobutamine stress echocardiography. J. Am. Coll. Cardiol. 34, 998-1004.

Lessick, J., Mutlak, D., Rinkevich, D., Markiewicz, W. and Reisner, S.A. (2000) Prospective study of early atropine use in dobutamine stress echocardiography. Eur. J. Echocardiogr. 1, 257-262.
Liang, C.S. and Hood, W.B. Jr. (1979) Dobutamine infusion in conscious dogs with and without autonomic nervous system inhibition: effects on systemic hemodynamics, regional blood flows and cardiac metabolism. J. Pharmacol. expt. Ther. 211, 698-705.

Martin, B.B., Reef, V.B., Parente, E.J. and Sage, A.D. (2000) Causes of poor performance of horses during training, racing, or showing: 348 cases (19921996). J. Am. vet. med. Ass. 216, 554-558.

McNeill, A.J., Fioretti, P.M., El-Said, S.M., Salustri, A., Foster, T. and Roelandt, J.R. (1992) Enhanced sensitivity for detection of coronary artery disease by addition of atropine to dobutamine stress echocardiography. Am. J. Cardiol. 70, 41-46.

Olsen, C.E., Porter, T.R., Deligonul, U., Xie, F. and Anderson, J. (1994) Left ventricular volume changes during dobutamine stress echocardiography identify patients with more extensive coronary artery disease. J. Am. Coll. Cardiol. 24, 1268-1273.

Pellikka, P.A., Roger, V.L., McCully, R.B., Mahoney, D.W., Baily, K.R., Seward, J.B and Tajik, A.J. (1995) Normal stroke volume cardiac output responses during stress echocardiography in subjects without left ventricular wall motion abnormalities. Am. J. Cardiol. 76, 881-886.

Pierard, L.A., Berthe, C., Albert, A., Carlier, J. and Kulbertus, H.E. (1989) Hemodynamic alterations during ischemia induced by dobutamine stress testing. Eur. Heart J. 10, 783-790.

Reef, V.B. (2001) Stress echocardiography and its role in performance assessment Vet. Clin. N. Am.: Equine Pract. 17, 179-189.

Reef, V.B., Lalezari, K., De Boo, J., van der Belt, A.J., Spencer, P.A. and Dik, K.J. (1989) Pulsed-wave Doppler evaluation of intracardiac blood flow in 30 clinically healthy Standardbred horses. Am. J. vet. Res. 50, 75-83.

Secknus, M.A. and Marwick, T.H. (1997) Evolution of dobutamine echocardiography protocols and indications: safety and side effects in 3,011 studies over 5 years. J. Am. Coll. Cardiol. 29, 1234-1240.

Smith, J.J. and Kampine, J.P. (1984) In: Circulatory Physiology: The Essentials. Williams and Wilkins, Baltimore. pp 116-119.

Stadler, P., Kinkel, N. and Deegen, N. (1994) Ein Vergleich der Herzminutenvolumenbestimmung zwischen der Thermodilutionsmethode und der PW-Doppler-Echokardiographie zur Beurteilung der systolischen Herzfunktion beim Pferd. Dtsch. Tieraerztl. Wochenschr. 101, 312-315.

Stump, G.L., Wallace, A.A., Gilberto, D.B., Gehret, J.R. and Lynch, J.J. Jr. (2000) Arrhythmogenic potential of positive inotropic agents. Basic Res. Cardiol. 95, 186-198.

Tuttle, R.R. and Mills, J. (1975) Dobutamine: development of a new catecholamine to selectively increase cardiac contractility. Circ. Res. 36, 185-196. 
